\title{
EDUCAÇÃO INFANTIL: UMA REFLEXÃO PLURAL DA HISTÓRIA E DA SEXUALIDADE
}

\author{
EDUCACIÓN DE LA PRIMERA INFANCIA: UN REFLEJO PLURAL DE LA \\ HISTORIA Y LA SEXUALIDADE
}

\author{
EARLY CHILDHOOD EDUCATION: A PLURAL REFLECTION OF HISTORY AND \\ SEXUALITY
}

\author{
Solange Aparecida de Souza MONTEIRO ${ }^{1}$ \\ Letícia Jovelina STORTO
}

RESUMO: Este texto estuda a história da educação infantil e da sexualidade, indicando a necessidade de se tecer reflexões a respeito dessa questão como forma de aprofundar o conhecimento acerca do conceito de infância e de sexualidade que é posta em prática no cotidiano familiar e escolar. Assim, discute-se sobre a importância de se trabalhar a educação sexualidade e debater sobre a sexualidade da criança (aquela entre 0 e 6 anos de idade) de forma positiva. Partindo do pressuposto de infância como "in-fans", ou seja, aquele que não fala e buscando compreender os múltiplos significados desse "não falar", o trabalho aponta ainda para a necessidade de se abrir espaço para discutir a infância e a criança em suas relações familiares e dentro do contexto escolar, especialmente no que tange à sua sexualidade.

PALAVRAS-CHAVE: Infância. Sexualidade infantil. História da infância. Construção social.

RESUMEN: este texto estudia la historia de la educación infantil y la sexualidad, indicando la necesidad de tejer reflexiones sobre este tema como una forma de profundizar el conocimiento sobre el concepto de infancia y sexualidad que se pone en práctica en Vida familiar y escolar. Por lo tanto, se discute la importancia de la educación sexual en el trabajo y la discusión de la sexualidad del niño (el de 0 a 6 años de edad) de manera positiva. Partiendo de la asunción de la niñez como "in-fans", es decir, el que no habla y busca entender los múltiples significados de este "no hablar", la obra también apunta a la necesidad de abrir el espacio para discutir la niñez y el niño en sus relaciones Familia y dentro del contexto escolar, especialmente con respecto a su sexualidad.

PALABRAS CLAVE: Niñez. Sexualidad infantil. Historia de la niñez. Construcción social.

\footnotetext{
${ }^{1}$ Instituto Federal de São Paulo (IFSP), Araraquara - SP - Brasil. Pedadoga. Mestra em Processos de Ensino, Gestão e Inovação pela Universidade de Araraquara - UNIARA (2018). Membro dos núcleos: -Núcleo de Gêneros e Sexualidade do IFSP (NUGS); Núcleo de Apoio às Pessoas com Necessidades Educacionais Específicas (NAPNE). ORCID: <http://orcid.org/0000-0002-1640-0266>.E-mail: solmonteiro@ifsp.edu.br ${ }^{2}$ Universidade Estadual do Norte do Paraná (UENP), campus de Cornélio Procópio, Cornélio Procópio, Paraná, Brasil. Professora Adjunta, Centro de Letras, Comunicação e Artes. ORCID: <https://orcid.org/0000-0002-7175338X>. E-mail: leticiajstorto@gmail.com
} 
ABSTRACT: This text studies the history of childhood education and sexuality, indicating the need to weave reflections on this issue as a way to deepen knowledge about the concept of infancy and sexuality that is put into practice in Family and school life. Thus, it discusses the importance of working sexuality education and discussing the sexuality of the child (the one between 0 and 6 years of age) in a positive way. Starting from the assumption of childhood as "In-fans", that is, the one who does not speak and seeks to understand the multiple meanings of this "not speaking", the work also points to the need to open space to discuss childhood and child in their relations Family and within the school context, especially with regard to their sexuality.

KEYWORDS: Childhood. Child sexuality. History of childhood. Social construction.

\section{Breve apontamento do movimento histórico da educação infantil no Brasil}

Este estudo debate a educação infantil brasileira relacionando-a à sexualidade infantil, a fim de relacionar os temas. A sexualidade está ligada diretamente ao desenvolvimento da criança, proporcionando-lhe emoções, sentimentos, sensações de prazer e desprazer, assim como as transformações ocorridas com o tempo. Para tanto, realiza-se pesquisa uma discussão teórica fundamentada em pesquisa bibliográfica e documental.

Etimologicamente, a palavra "infância" tem origem no latim "infantia": deriva do verbo "fari”, que significa "falar" (SIGNIFICADOS, 2018, s/p). Assim, "fan” significa "falante" e o prefixo "in" constitui a negação do verbo, ou seja, a infância é a fase em que não se fala (SIGNIFICADOS, 2018, s/p). Por conseguinte, "infans" refere-se ao indivíduo que ainda não é capaz de falar. No decorrer da História da Humanidade, a criança recebeu múltiplas representações, cujo significado é dado à criança pelo adulto, pela representação construída na relação entre ambos (criança e adulto) e demais relações do adulto com o mundo e com outros adultos.

De acordo com Ribeiro (2004), nos séculos XVI, XVII e XVIII, a sexualidade predominantemente era tida como libidinosa para os homens e repressiva para as mulheres, tendo como pano de fundo regras e normas fundamentadas no catolicismo. Historicamente, a concepção de infância tem sido reconstruída e modificada, de modo a distintos valores sociais em diferentes períodos (BERNARTT, 2009; KRAMER, 1992). A autora ressalta que crianças são sujeitos sociais e históricos, marcados, portanto, pelas contradições das sociedades em que estão inseridas. Isso se reflete no conceito de infância, o qual tem sofrido modificações com o passar das gerações e das sociedades, permanecendo em constante construção e refletindo os valores presentes na sociedade em diferentes períodos históricos. 
Segundo Marafon (2009), o atendimento às crianças de 0 a 6 anos teve início no Brasil no final do século XIX, uma vez que, antes desse período, o atendimento às crianças de tal faixa etária em instituições como creches no país era praticamente inexistente. Na zona rural, onde vivia a maior parte da população até meados da década de 1960, as famílias de fazendeiros assumiam o cuidado das crianças abandonadas, geralmente fruto da exploração sexual da mulher negra e índia pelos fazendeiros e outros homens brancos (AQUINO, 2001; MARAFON, 2009).

Com a migração da população da zona rural para a zona urbana, em busca de melhores condições de vida, saúde, trabalho e escola, eram raras as iniciativas de proteção à infância na época. Assim, com o objetivo de combater as altas taxas de mortalidade infantil surgem as entidades de acolhimento no período precedente à República (OLIVEIRA, 2005).

No Brasil, a guarda das crianças era a principal função das primeiras instituições infantis, algo que sofreu poucas mudanças efetivas ao longo da História, de modo a permanecer essa visão equivocada dos papéis e concepções dessas instituições no país. Para maior compreensão sobre o assunto, Kramer (1987) divide o histórico do atendimento à infância no Brasil em períodos: de 1500 até 1874, as ações de fato realizadas foram mínimas e o papel das instituições era guardar as crianças; de 1874 a 1899, período profícuo de elaboração de projetos de grupos particulares, tais como médicos e igrejas, porém de pouca efetivação e mudança no conceito de educação infantil; de 1899 a 1930, criação de instituições e promulgação de leis para a regulamentação do atendimento à criança; e, finalmente de 1930 até 1980, período de importantes alterações na sociedade brasileira as quais promoveram um novo paradigma a respeito da infância e da educação infantil no país. Cumpre ressaltar que esses períodos apresentam concepção de criança e de sociedade distintos, de modo a interferir no atendimento dado à criança e à sua educação e representação em cada um deles, como foi brevemente descrito aqui.

A priori, no atendimento infantil, as creches também tinham um caráter assistencialista, pois almejavam apartar do trabalho servil as crianças pobres (KRAMER, 1987).

Ainda de acordo com a autora (1987, 1984), a partir da década de 1920, no Brasil, intensifica-se a abertura de fábricas e indústrias aliada à expansão do sistema capitalista no país, o que levou à necessidade de uma nova concepção disso, já que os operários reivindicavam melhores condições de vida e de educação para seus filhos. Assim, o atendimento das crianças que se encontravam expostas à exploração, à negligência e ao abandono dos pais exigia um olhar mais atento e a elaboração e implementação de ações que 
visassem a extinguir (ou ao menos diminuir) tais situações, todas muito prejudiciais aos infantes. Já as mulheres lutavam para um espaço e um lugar para cuidado de seus filhos no horário de trabalho. Inaugura-se, a partir desse período, um marco histórico: a primeira creche brasileira para filhos de operários na cidade do Rio de Janeiro (KRAMER, 1987, 1984).

Além disso tudo, havia outro impasse na educação infantil nacional e no atendimento às crianças: o dualismo, ou seja, havia a pré-escola para as crianças oriundas de classes abastadas, e existiam as creches para as crianças pobres (KRAMER, 1987), o que pode se perceber até nos dias atuais, infelizmente. Apesar de funcionarem, as instituições voltadas à classe mais simples funcionavam naquela época (e ainda funcionam), contudo o desenvolvimento cognitivo e educacional infantil não era prioridade, já que os aspectos pedagógicos não eram privilegiados. Acredita-se que em muitas instituições isso permanece, infelizmente, mas em menor grau, já que, nos últimos anos, políticas públicas incentivaram a formação docente para quem atua na educação infantil, ademais documentos que regulamentam têm guiado o atendimento dado às crianças em tais instituições. Naquele período, a função principal das creches era amparar e proteger as crianças, atendendo às suas necessidades básicas quando seus responsáveis não estavam presentes. A preparação para o mundo do saber era preterida. Ao contrário disso, crianças advindas de famílias mais abastadas tinham acesso às instituições que visavam à sua educação e desenvolvimento infantis. Essas instituições estavam pautadas em perspectivas mais pedagógicas, e nada assistencialistas.

Para Kuhlmann Jr. (2000), o ensino infantil ofertado à época não estava direcionado à emancipação e, em palavras mais atuais, ao empoderamento das crianças, ao contrário, direcionava-se à submissão e ao silenciamento infantis. $\mathrm{O}$ ensino era, portanto, assistencialista, respaldado numa "pedagogia da submissão", a qual "pretendia preparar os pobres para aceitar a exploração social. O Estado não deveria gerir diretamente as instituições, repassando recursos para as entidades" (KUHLMANN JR, 2000, p. 8). Além disso, somente a partir de 1980, órgãos públicos assumem projetos de educação sexual nas escolas (RIBEIRO, 2004), até aquele momento poucas ações foram tomadas a fim de que houvesse uma discussão efetiva acerca desse tópico.

Rousseau (1995), considerado um dos principais filósofos do Iluminismo e um dos primeiros pedagogos da História, em pleno século XVIII, apresenta um olhar diverso de criança. Sua proposta de ensino é libertadora, uma Pedagogia (do) Natural, que se volta à criança e à sua autonomia. Nessa pedagogia, o filósofo enfatiza a necessidade de o ensino infantil formar a criança para se tornar um indivíduo (futuro) independente, responsável por 
seu destino. Para isso, ela precisa estar livre, sem amarras, o que gerará, certamente, dificuldades, frustrações, os quais são considerados elementos necessários para o amadurecimento, crescimento e aprendizado da criança, porque "as crianças do povo, mais livres, mais independentes, são geralmente menos doentias, menos delicadas, mais robustas do que as que pretendem educar contrariando-as sem cessar" (ROUSSEAU, 1995, p.39). Para isso, é criado por Rousseau (1995) o personagem Emílio, utilizado para exemplificar e esclarecer as ideias do autor em seu texto. Emílio é livre para aprender, para brincar, para viver, para crescer com seus erros e acertos. Sobre o personagem, o filósofo esclarece: "quanto às regras que poderiam ter necessidade de provas, apliquei-as todas a meu Emílio ou a outros exemplos e mostrei em pormenores assaz precisos como o que eu estabelecia podia ser praticado" (ROUSSEAU, 1995, p. 24). Para o filósofo, as ciências e a razão são fundamentais no processo de ensino/aprendizagem das crianças. Assim, cabe ao professor (e também aos pais) trabalhar de modo a criança ter acesso a tais elementos e também de estimular o prazer por eles: "Não se trata de ensinar-lhe as ciências e sim de dar-lhe inclinação para as amar e métodos para as aprender, quando a inclinação se tiver desenvolvido bastante. Eis certamente um princípio fundamental de uma boa educação" (ROUSSEAU, 1995, p. 136).

Sobre a educação de crianças, Durkheim (1978), em seu contexto (França, fim do século XIX), afirma que o objetivo era moralizá-la. Para isso, era preciso inculcar nela os três pilares da moralidade: disciplina, abnegação (num sentido altruísta) e autonomia da vontade (espécie de submissão esclarecida). Com essa finalidade, certamente a educação sexual não seria um tema de interesse, sendo silenciado. Assim, nota-se que, apesar de mais anos de experiência, outros países também demoraram para incluir o debate sobre a sexualidade infantil no ensino; outras nações relutam até hoje em fazê-lo.

O Brasil, hoje, mostra uma tendência para o conservadorismo em que projetos como o "Escola sem Partido", Projeto de Lei nº67, de 2015 (BRASIL, 2015), e a recusa por uma discussão sobre a educação sexual na escola, seja nos anos finais do ensino fundamental, seja no ensino médio, têm sido frequentes, algo certamente assustador e retrógado, que só serve para prejudicar ainda mais a educação dessas crianças, as quais são privadas cada vez mais de discutir um tópico que poderia lhes auxiliar no autoconhecimento e também na compreensão de assédio sexual, podendo aprender a identificá-lo e a denunciá-lo a seus professores. Isso porque o tema sexualidade está diretamente vinculado à diversidade de valores da sociedade. Essa tendência conservadora pode ser observada na escola dos ministros vinculados às áreas de educação e de direitos humanos indicados pelo próximo presidente brasileiro, assim em 
seus discursos. Como as dimensões humanas, sociais e culturais estão relacionadas à sexualidade bem como a questões educativas, o discurso oficial sobre tais temas é, sem dúvida, um termômetro para avaliar o assunto. Para exemplificar, segue um trecho do Projeto de Lei nº67, de 2015 (BRASIL, 2015, p. 5),

É fato notório que professores e autores de livros didáticos vêm se utilizando de suas aulas e de suas obras para tentar obter a adesão dos estudantes a determinadas correntes políticas e ideológicas; e para fazer com que eles adotem padrões de julgamento e de conduta moral - especialmente moral sexual - incompatíveis com os que lhes são ensinados por seus pais ou responsáveis. (grifos nossos).

No trecho, percebe-se que o objetivo do projeto de lei é, novamente, silenciar a discussão sobre sexualidade nas escolas, uma vez que muitos políticos brasileiros vêm a educação sexual científica trabalhada hoje nas salas de aulas como incompatível com a moral de pais e responsáveis por essas crianças (BRASIL, 2015). O documento deixa de lado uma questão basilar: a violência sexual contra crianças e adolescentes, hoje no país, é provocada principalmente por familiares (37\% dos casos notificados de 2011 a 2017) ou pessoas próximas às vítimas/amigos/conhecidos $(27,6 \%)$ e ocorrem na residência das crianças em grande parte das vezes $(69,2 \%$ dos casos) (BRASIL, 2018). Em apenas 6,5\% dos casos analisados os agressores são desconhecidos de suas vítimas.

Os dados comprovam que discutir sexualidade e educação sexual é urgente hoje no país. Também não se pode mais ignorar que a criança apresenta um corpo sexuada, que é, há muito, alvo de interesse de pessoas mal-intencionadas. Assim, na próxima seção, discute-se a questão de gênero, corpo e prazer na infância.

\section{Corpo sexuado: gênero, corpo e prazer}

O trabalho com a sexualidade com as crianças não significa distanciar-se dos fundamentos pedagógicos, os quais devem ser considerados no campo educacional. Ao contrário, faz-se mister utilizá-los para fundamentar a discussão com as crianças sem "achismos" e preconceitos, apresentando-lhes informações coerentes e de modo adequado.

Em conversas com crianças sobre sua sexualidade, muitas vezes a terminologia sobre órgãos e atos sexuais é alterada, omitida, encoberta, de modo que as genitálias e os atos sexuais são tratados como coisas "feias", "sujas", "proibidas", que não devem ser valorizados como as demais partes do corpo, no caso das genitálias, usando-se eufemismos para designálas e às atividades sexuais. A repressão com as genitálias femininas é ainda maior e mais 
visível e, como consequência, apresenta-se a imagem negativa que a maioria das mulheres têm da sua vulva, imagem que, geralmente, é projetada durante toda a infância da mulher. O desconforto em se utilizar os nomes corretos dos genitais está nos adultos, e não nas crianças.

Além disso, a ereção dos meninos e o toque nos genitais por parte das crianças, em situações de brincadeiras e descobertas, são manifestações da sexualidade infantil e que costumam constranger, incomodar ou preocupar apenas aos adultos, pois grande parte das pessoas não sabe lidar de forma tranquila com tais situações.

As descobertas infantis fazem parte do desenvolvimento psicológico e sexual saudável de a criança descobrir todo o seu corpo, incluindo as genitálias. Ela toca seu corpo porque sente prazer ao tocá-lo, e não deve ser privada dessa experiência. Durante a descoberta do corpo da criança por ela mesma, o toque pode acontecer com as mãos, pela fricção dos genitais em objetos, como almofadas, no sofá, no chão ou por meio de outras brincadeiras.

Ao se tratar de temáticas como masturbação, deve-se perceber que é natural a criança buscar uma satisfação prazerosa nesse ato ou tentar melhor compreendê-lo. Como as demais aprendizagens da criança, a masturbação também é algo que tem lugar e frequência adequados para acontecer, algo que deve lhe ser ensinado. A prática excessiva da masturbação por crianças pode ser indício de ela esteja vivenciando conflitos difíceis de manifestar por outros caminhos, de forma que a masturbação, nesses casos, é uma maneira encontrada pela criança de extravasar-se aquilo que não encontra outra fonte de expressão. Assim, responsáveis pela criança e professores devem estar atentos e encaminhá-la à orientação especializada.

A curiosidade e a ludicidade são duas importantes características das crianças, o que desperta interesse pelo seu corpo e pelo corpo do outro. Por volta dos dois a quatro anos, é comum a criança descobrir e brincar com os seus genitais e, às vezes, com os genitais dos seus pares. Assim, o momento em que a criança busca conhecer o seu corpo espontaneamente é adequado para lhe ensinar a noção de privacidade entre o que se convém fazer em público e no privado. Nesse instante, também é preciso ter sensibilidade para saber investigar se ela não está com alguma coceira ou infecção, cabendo ao educador (pais, responsáveis pela criança ou professor), explicar amorosamente que tocar nos genitais é agradável. Tratar o assunto com naturalidade é muito importante para não criar barreiras nem tabus. Deve-se também indicar o que é adequado e o que não é, como que locais são apropriados para isso (o toque), como o quatro, o banheiro, ou seja, em ambientes particulares.

Em muitos desses momentos de autoconhecimento corporal, a ação ajuda a criança a se acalmar, uma vez que ela, em geral, não tem consciência daquilo que faz, ou seja, de tocar 
seus genitais. Não há, portanto, "maldade”, já que a criança desconhece a ideia de sexualidade como entendida por um adulto. Fundamentada nos estudos de Freud, Kupfer (1989, p. 39) afirma sobre isso que "a sexualidade é mais ampla que a sexualidade genital. Inclui as preliminares do ato sexual, as perversões, as experiências sensuais da criança vividas em relação ao seu próprio corpo ou em contato como corpo da mãe".

Retomando Freitas (2011), Moreira (2018, p. 28) fala sobre a necessidade de a criança se tocar, conhecer seu próprio corpo. "Essa busca exploratória permite que a criança se desenvolva com desembaraço, orgulho, prazer e carinho por si e pelo seu bem maior, que é o corpo". Com isso, a criança aprenderá a se respeitar e valorizar, assim como a respeitar e valorizar o corpo do outro, além de prezar, cuidar e se responsabilizar por esses corpos e sexualidades, sem distinção de gênero (MOREIRA, 2018).

Quando esse tipo de situação acontecer em lugares públicos, a atitude mais apropriada é atrair a atenção da criança para uma atividade interessante que possa distraí-la e apenas quando estiver a sós com ela, é que será o momento de orientá-la carinhosamente, conforme apontado anteriormente. A fase de descobrimento do corpo da criança é o momento propicio de se trabalhar a prevenção da violência sexual, o toque adequado e o inadequado. Não se deve confundir a sexualidade infantil com a sexualidade adulta.

Deve-se orientá-la a não deixar ninguém tocar no seu corpo a não ser seu responsável e outros adultos na presença do responsável. Esclarecê-la de que somente as pessoas muito próximas a ela e que são responsáveis pelos cuidados com a sua higiene, isto é, que podem tocar no seu corpo e lavar suas partes íntimas, para que a criança perceba os "toques do sim" e os "toques do não" e que se posicione de forma adequada e segura quando ocorrerem tais toques.

Todavia, deve-se intervir quando essa atividade se torna compulsiva. Esses casos podem desencadear sinais de ansiedade e de que alguma coisa não está bem com a criança, ou seja, problemas emocionais, sentimento de solidão, carência afetiva, gravidez da mãe, vermes, higiene inadequada dos órgãos genitais, infecções urinárias ou irritação no órgão genital ou mesmo situações de violência sexual podem levar ao exagero em tais práticas, o que deve ser investigado.

É importante refletir sobre as lembranças da infância e os sentimentos e emoções que essas lembranças ainda carregam, pois elas têm uma forte influência na forma como a pessoa percebe a si mesma e o mundo e de como ela reage diante de situações que envolvem esses tipos de manifestações da sexualidade infantil. 
Ao encontrar-se espaço para se fazer algo contra ou agir de modo irregular, meninas e meninos vão além dos limites do que é imposto pela sociedade para cada sexo, desejam brinquedos diferentes daqueles que foram determinados e buscam outros sentidos, significados para a cultura na qual estão inseridos, demonstrando formas diferentes de relacionamento. Ao contradizerem as expectativas dos adultos, meninas e meninos trazem desafios às suas vidas, criam novas formas de relações que se desestabilizam e trazem novas formas de olhar para o que é considerado condição normal.

A positividade das violações no modo como resistem aos modelos antecipadamente estabelecidos, quando anunciam seus desejos, são reinventadas e recriadas de distintas maneiras de brincar, desmistificando o que é de menino ou menina, de modo que o objeto passa a ser ressignificado e alvo de desconforto e inquietação para aqueles que querem manter o padrão estabelecido pela sociedade.

Ainda na educação infantil, são importantes para o desenvolvimento das crianças a fantasia e a imaginação, sendo saudáveis e necessárias para o desenvolvimento psicossexual infantil. Os jogos também acontecem entre crianças do mesmo sexo, por simples curiosidade, sem que isso tenha alguma conotação de homossexualidade tampouco um desejo erotizado. É importante, em momentos como esse, o adulto manter-se sereno, convidar as crianças para se vestirem e conversar com elas calmamente, procurando compreender do que elas brincavam e quais os motivos que a levaram a brincar daquele modo.

Buscar satisfazer a curiosidade da criança, apresentando as diferenças do corpo do menino e da menina por meio de livros, bonecos, bonecos sexuados ou ainda aproveitar situações do contexto cotidiano, como, por exemplo, a hora do banho do bebê, que é um momento propício para conversar com a criança e mostrar as diferenças do corpo de menino e de menina.

Ademais, a criança sente-se atraída por simbologias que vê no ambiente familiar e na mídia e tende a repeti-las, como o beijo na boca, que é uma expressão de carinho típica do adulto e, algumas vezes, imitada pelas crianças. Sobre namoro, costuma acontecer por volta dos 5 ou 6 anos, porém sem o mesmo sentido do namoro adolescente ou adulto. Trata-se, na verdade, mais de um comportamento imitativo do adulto. Deve-se observar sem desprezar ou supervalorizar a situação, apenas deixar que a criança viva a fantasia dentro da sua realidade infantil. Quando se trata da nudez em família, é algo natural para a criança durante os três primeiros anos de vida. Assim, elas não fazem julgamento moral acerca da nudez tampouco exibem qualquer tipo de vergonha ou desconforto diante dela. Observar e perceber-se o 
sentimento dos pais, sendo ele confortável, não há problemas em se tomar banho com a criança, porém, caso não se senta confortável, é recomendável não forçar a situação.

Com a chegada de um novo bebê, a criança deve ser a primeira a saber da notícia pelos pais. É importante compreender as emoções contraditórias pelas quais a criança passa e saber lidar com elas, aceitar com tranquilidade possíveis sentimentos de ódio, raiva, inveja e ciúmes, assim como saber identifica-los e nomeá-los às crianças (dizer a elas o que está sentindo dando nome ao sentimento). É importante que a criança viva esses sentimentos e que possa expressá-los sem condenação e repressão.

No que tange à intimidade e à a espontaneidade sexual do pais, é importante mantêlas, de modo a se consolidarem os momentos de privacidade e intimidade, o que favorece a qualidade do sono, assegura a manutenção de espaço importante para resolução de conflitos do casal, mas sempre com o cuidado de privar a criança de tais situações.

Em relação ao compartilhamento do mesmo ambiente de repouso noturno, é desaconselhável que as crianças durmam no mesmo quarto que os pais e que esse tipo de situação faça parte da rotina da família, de vez em quando a cama do casal pode ser um momento de aconchego. Situações mais pontuais em que essa regra pode e deve ser quebrada são: se a criança estiver doente, necessitando de cuidados especiais, em caso de luto na perda de alguém muito próximo e querido da criança, pois é importante que ela se sinta acolhida, em situações de perigo e de pesadelos, entre outros.

Para Weeks (1999), o gênero é condição social por meio da qual os sujeitos são identificados e categorizados como homem ou mulher, de modo que é transgressão cruzar as fronteiras que delimitam o que é ser homem e o que é ser mulher em dada sociedade e época. Disso derivam questões como cores que representam cada gênero (rosa para mulheres, azul para homens), funções de trabalho e de trato familiar e doméstico, profissões, atividades de lazer, entre outros.

Refletir sobre os fundamentos dessas afirmações no âmbito da educação e, mais especificamente, da educação infantil, exige o questionamento de suas origens e do peso do caráter biológico na construção das diferenças. Isso pressupõe, por exemplo, indagar a respeito da interferência e do papel da cultura nos processos de socialização e de formação de meninas e meninos desde suas primeiras experiências de vida na família e na instituição escolar (VIANNA; FINCO, 2009, p. 268).

Moreira (2018, p. 18) afirma que, apesar das muitas pesquisas que buscam desmistificar e desconstruir isso, 
Muitos tabus ainda influenciam o modo de enxergar a sexualidade das crianças. As proibições relacionadas a tudo que se refere à sexualidade estão muito presentes nas práticas pedagógicas, seja no tocante ao controle e dominação do corpo ou à tentativa de heterossexualização das crianças. Além disso, são evidentes os malefícios que a heteronormatividade tem trazido à nossa sociedade, tendo em conta que mulheres são vistas como submissas, e homens são obrigados a reforçar, nas mais diversas situações, sua masculinidade, o que se caracteriza não somente como violência simbólica (BOURDIEU, 1999), mas também como violência física. [...] Essas práticas sexistas devem, portanto, ser questionadas e contestadas.

Isso posto, o que não deve acontecer é ausência de discussão sobre sexualidade, que se mostra mais que necessária. Deve-se, ao contrário, favorecer esse debate e a educação sexual nas escolas. Nesse contexto, os termos sexualidade e sexualização não devem ser confundidos, pois "ao mesmo tempo em que nossa sociedade cria leis e sistemas de proteção à infância e adolescência contra a violência sexual, ela legitima determinadas práticas sociais contemporâneas", como a exibição sexualizada de corpos de crianças de adolescentes nas mídias digitais, televisivas e impressas (FREITAS, 2011, p. 167).

Foucault $(1999,1985)$ desvela se o que se fez da infância e como a infância se apresenta na atualidade e o que se diz sobre a criança e sobre sua própria história que acaba sendo notadamente assinalada pela percepção de uma infância que não se enquadra a tempo algum, inocente e ingênua e sem lugar de fala e escuta. Para Foucault, a infância tem sido pautada e construída em um modelo científico e institucional objetificado, adornado e subordinado a políticas e legislações educacionais em um arcabouço de estruturas e de infância e em função de escolas para crianças.

As definições da infância estão naturalizadas, o que impede o desenvolvimento de sua construção histórica, questionada, sem problematização, descolada do fluxo que se fez inventada. Os discursos sobre a criança são impositivos, encapsulados pela generalização do que é ser um sujeito infantil, camuflado de formas multifacetadas que vêm sendo, ao longo do tempo, instituídas. Prepondera uma disposição para exclusão, o questionamento, a problematização e o autorretrato, entendido como um enfrentamento de uma realidade nova do conhecido construído e de um não conhecimento (RESENDE, 2010).

\section{Sexualidade: falar, nunca calar}

As significações da infância muitas vezes não são tomadas de um modo naturalizado, o que impede que seja pensada como construção histórica, como algo a ser problematizado, indagado, despregado da forma corrente como é concebida. Os discursos sobre a criança 
impõem uma generalização do que é ser um sujeito infantil, as várias infâncias camuflam aquilo que tem sido constituído ao longo do tempo. Predomina, assim, uma tendência para excluir a indagação, o questionamento, a problematização e o próprio pensamento, entendido como afrontamento de uma realidade nova.

Por isso, uma das preocupações dos pais é de eles não saberem que palavras usar quanto tiverem de orientar seus filhos sobre questões relativas à sexualidade, especialmente se os filhos forem crianças, temendo responder "coisas a mais" do que aquilo que a criança poderia ou deveria saber e sentirem-se desconfortáveis diante desses assuntos, pensarem que podem "despertar" ou aumentar a curiosidade da criança sobre "assuntos impróprios" para sua idade, recearem que a criança comente com seus pares e com o mundo. É preciso entender que falar sexualidade é mais do que falar apenas de um comportamento sexual, é também trazer sentimentos de uma identidade que se desenvolve durante toda a vida da pessoa. Assim, o assunto deve ser tratado com naturalidade desde que surgem os primeiros sinais de interesse e/ou curiosidade por parte do infante.

No caso dos professores, eles têm ainda o agravante do receio da reação da família. Não é necessário ser "um especialista" nesses assuntos para responder às perguntas das crianças. O mais importante nessas situações é a criança perceber que os docentes são acessíveis, "são perguntáveis". Ao se responder às perguntas das crianças, é interessante se ter em consideração que, geralmente, ela já viu ou ouviu alguma coisa relacionada com aquilo que ela está perguntando.

Uma estratégia interessante é devolver a pergunta para a criança e perceber o que ela realmente já sabe ou ouviu sobre o assunto ou para identificar com mais clareza o que ela deseja saber. Não se deve preocupar em se responder "a mais", pois a criança assimilará apenas aquilo que lhe interessa e que tem capacidade de abstrair. Para assegurar-se de que não respondeu "a menos", deve-se perguntar se ela compreendeu, se tem mais alguma dúvida, se gostaria de perguntar mais alguma coisa. Aproveitar para elogiar a pergunta que a criança fez ajudará a fortalecer a relação de confiança, os vínculos e abrirá espaços para o diálogo.

Por meio das produções simbólicas do brincar e do desenho, as perguntas fluem naturalmente aos pais e aos professores, de modo que a criança passa a representar e ressignificar seu contexto e as informações recebidas pelos adultos mediante essas estratégias lúdicas.

\section{Considerações finais}


Este texto procurou estabelecer uma relação da História da educação infantil no Brasil ao modo como foi e tem sido construída a sexualidade infantil e sua importância para o desenvolvimento da criança, uma vez que, a partir da compreensão desse tema, a família, o professor e a escola podem trabalhar e orientar de forma significativa a descoberta da sexualidade da criança e suas manifestações. A criança expressa sua sexualidade a partir de seu comportamento afetivo e social. Desde o nascimento, a criança explora o prazer, por meio dos contatos afetivos e das relações com o mundo externo. Com isso, o professor é chamado à reflexão de seu plano de aula, das ocorrências espontâneas no cotidiano escolar com atividades que promovam aprendizagens em relação a corpo, gênero e sexualidade, especialmente na educação infantil. O desenvolvimento de tal processo requer, sobretudo, formação, romper com a acomodação e a alienação. Assim, o educador deve estar atento e se conscientizar de todas as mudanças ocorridas na criança para orientá-la na descoberta da sexualidade e no seu papel na sociedade.

Esse assunto não costuma ser abordado nos cursos de Pedagogia para os futuros professores em formação, mas tem se tornado cada vez mais necessário dentro das salas de aula, já que a realidade escolar exige melhor compreensão da sexualidade infantil. Essa não é uma tarefa fácil de ser realizada. Entretanto, observa-se que durante o trabalho formativo, o educador constrói barreiras contra-argumentos que venham de encontro aos conceitos que possui, mostrando uma intensa resistência. A sexualidade infantil apresenta uma autenticidade, porque as crianças de modo algum precisam provar a quem quer que seja e também não estão preocupadas com os padrões de normalidade que a sociedade impõe aos adultos.

É de fundamental importância que, na educação de crianças, a família e a escola possam estabelecer relações entre sexualidade e educação com objetivos de conhecer os significados produzidos e manifestados e que, por meio dela, possam fazer conexões com os conhecimentos expressos pelas crianças e que suas descobertas possam ocorrer de maneira prazerosa. A criatividade e curiosidade infantil devem ser tratadas com naturalidade e transformadas em novos conhecimentos.

\section{REFERÊNCIAS}

AQUINO, Lídia. As políticas sociais para a infância a partir de um olhar sobre a história da criança no Brasil. In: ROMAM, E. D.; STEYER, V. E. (Org.). A criança de 0 a 6 anos e a educação infantil: um retrato multifacetado. Canoas, RS: Ulbra, 2001. 
BENTO, Berenice. As tecnologias que fazem os gêneros. CONGRESSO

IBEROAMERICANO DE CIÊNCIA, TECNOLOGIA E GÊNERO, 7, 2010, Curitiba.

Anais... Curitiba: Ed. da UTFPR, 2010.

BERNARTT, Roseane Mendes. A infância a partir de um olhar sócio-histórico. In:

CONGRESSO NACIONAL DE EDUCAÇÃO - EDUCERE, 9, 26 a 29 out. 2009. Anais... Curitiba: PUCPR. Disponível em:

http://www.pucpr.br/eventos/educere/educere2009/anais/pdf/2601_1685.pdf. Acesso em: 10 dez. 2018.

BOURDIEU, Pierre. A dominação masculina. Rio de Janeiro: Bertrand Brasil, 1999.

BRASIL. Ministério de Educação e do Desporto. Referencial curricular nacional para educação infantil. Brasília, DF: MEC, 1998.

BRASIL. Câmara dos Deputados. Projeto de lei $\mathbf{n}^{\mathbf{0}}$ 867, de 2015. Inclui, entre as diretrizes e bases da educação nacional, o "Programa Escola sem Partido". Disponível em: http://www.camara.gov.br/sileg/integras/1317168.pdf. Acesso em: dez. 2018.

BRASIL. Secretaria de Vigilância em Saúde, Ministério da Saúde. Análise epidemiológica da violência sexual contra crianças e adolescentes no Brasil, 2011 a 2017. Boletim

Epidemiológico, Brasília, n.27, vol. 49, jun. 2018. Disponível em:

http://portalarquivos2.saude.gov.br/images/pdf/2018/junho/25/2018-024.pdf. Acesso em: dez. 2018.

DURKHEIM, Émile. Educação e Sociologia. São Paulo: Melhoramentos, 1978.

FINCO, Daniela. Educação infantil, espaços de confronto e convívio com as diferenças: análise das interações entre professoras e meninas e meninos que transgridem as fronteiras de gênero. 2010. 216f. Tese (Doutorado em Educação) - Universidade de São Paulo. São Paulo, 2010.

FOUCAULT, Michel. História da sexualidade: o cuidado de si. Rio de Janeiro: Edições Graal, vol. III, 1985.

FOUCAULT, Michel. História da sexualidade: a vontade de saber. 13. ed. Rio de Janeiro, RJ: Graal, v.1., 1999.

FREITAS, Maria José de. Orientação sexual na escola: desmistificando a educação em sexualidade no espaço escolar. In.: FINCO, Daniela; SOUZA, Adalberto dos S.; OLIVEIRA, Nara R. (Orgs.). Educação e resistência escolar: gênero e diversidade na formação docente. São Paulo: Alameda, 2017, p.133-156. Disponível em:

http://painelacademico.uol.com.br/conteudo//pdf/405d4de449241e714db2ce79832ddd146d96 1cbc.pdf. Acesso em: dez. 2018.

INFÂNCIA. In: Significados. Disponível em: https://www.significados.com.br/infancia/. Acesso em: dez. 2018.

KRAMER, Sônia. A política do pré-escolar no Brasil: a arte do disfarce. 7.ed. São Paulo: Cortez, 2003. 
KUHLMANN JR, Moysés. Educação infantil e currículo. In: FARIA, Ana Lúcia Goulart de; PALHARES. Marina Silveira (Orgs.). Educação infantil pós LDB: rumos e desafios. São Paulo: Autores Associados, 1999.

KUHLMANN JR, Moysés. Histórias da educação infantil brasileira. Revista Brasileira de Educação, n.14, p.5-19, Maio/Jun./Jul./Ago. 2000.

KUHLMANN JR, Moysés. Infância e Educação infantil: uma abordagem histórica. Porto Alegre: Mediação, 2010.

KUPFER, Maria Cristina. Freud e a educação: o mestre do impossível. São Paulo: Scipione, 1989.

MARAFON, Danielle. Educação infantil no Brasil: um percurso histórico entre as idéias e as políticas públicas para a infância. In: Seminário Nacional De Estudos E Pesquisas História Sociedade E Educação No Brasil, 7, 2009, Campinas, SP. Anais... Campinas: Unicamp, 2009.

MOREIRA, Danielle de Mello. Sexualidade das crianças pequenas e educação infantil: desafios emergentes em tempos de censura. 2018. 61f. Trabalho de Conclusão de Curso (Graduação em Pedagogia) - Universidade Federal de São Paulo. Guarulhos, 2018.

OLIVEIRA, Zilma de Moraes Ramos. Educação Infantil: fundamentos e métodos. 2.ed. São Paulo: Cortez, 2005.

RESENDE, Haroldo de. Notas sobre modernidade, pedagogia e infância a partir de Michel Foucault. ETD - Educ. Tem. Dig., Campinas, v.12, n.1, p. 242-255, jul./dez. 2010.

RIBEIRO, Paulo Rennes Marçal. Educação sexual além da informação. São Paulo: E.P.U., 1990.

RIBEIRO, Paulo Rennes Marçal. Momentos históricos da Educação Sexual no Brasil. In: Sexualidade e educação: aproximações necessárias. São Paulo: Arte \& Ciência, p. 15- 25, 2004.

ROUSSEAU, Jean-Jacques. Discurso sobre a origem e os fundamentos da desigualdade entre os homens. 5.ed. Trad. de Lourdes Santos Machado. São Paulo: Nova Cultural, 1991.

ROUSSEAU, Jean-Jacques. Emílio ou da educação. 3.ed. Trad. de Sérgio Milliet. Rio de Janeiro: Bertrand Brasil, 1995.

VIANNA, Cláudia; FINCO, Daniela. Meninas e meninos na educação infantil: uma questão de gênero e poder. Cadernos Pagu, p. 33, p. 265-283, 2009. Disponível em: http://www.scielo.br/pdf/cpa/n33/10.pdf. Acesso em: dez. 2018.

WEEKS, Jeffrey. O corpo e a sexualidade. In: LOURO, Guacira (Org.). O corpo educado. Trad. de Tomaz Tadeu da Silva. Belo Horizonte: Autêntica, 1999, p.35-82. 


\section{Como referenciar este artigo}

MONTEIRO, S. A. de S.; STORTO, L. J.; RIBEIRO, P. R. M. Educação infantil: uma reflexão plural da história e da sexualidade. Revista Ibero-Americana de Estudos em Educação, Araraquara, v. 14, n. 1, p. 237-252, jan./mar., 2019. E-ISSN: 1982-5587. DOI: 10.21723/riaee.v14i1.11865

Submetido em: 10/04/2018

Revisões requeridas: $15 / 07 / 2018$

Aprovado em: 23/18/2018 